\title{
Development of Magnetorheological Engine Mount Test Rig
}

\author{
Mohd Razali Md Yunos ${ }^{1,}$, Mohamad Hafiz $\operatorname{Harun}^{1}$, M. Z. Sariman ${ }^{2}$, and A. K. Mat Yamin ${ }^{2}$ \\ ${ }^{1}$ Faculty of Engineering Technology, Universiti Teknikal Malaysia Melaka, Malaysia \\ ${ }^{2}$ Faculty of Mechanical Engineering, Universiti Teknikal Malaysia Melaka, Malaysia
}

\begin{abstract}
Ride comfort is an important factor in any road vehicle performance. Nonetheless, passenger ride comfort is sometimes affected by the vibrations resulting from the road irregularities. Vehicle ride comfort is also often compromised by engine vibration. Engine mount is one of the devices which act as vibration isolator from unwanted vibration from engine to the driver and passengers. This paper explains the development of the test rig used for laboratory testing of Magnetorheological (MR) engine mount characterization. MR engine mount was developed to investigate the vibration isolation process. An engine mount test machine was designed to measure the displacement, relative velocity and damper force with respect to current supply to characterize the hysteresis behavior of the damper and as force tracking control of the MR engine mount.
\end{abstract}

\section{Vehicle engine mounting system}

Engine performance is measured based on power-to-weight ratio value in which the higher value represents high performance. Hence, car manufacturer focus on development of small-sized engine to reduce fuel consumption and emission gasses. Additional power recovery devices such as turbocharger and supercharger are implemented to compensate the loss power. As a result, greater engine vibration will be caused by the unbalance force generated by reciprocating piston movement and the combustion pressure. Thus, engine mounts is a proper device used to isolate the vibration from the engine to the chassis.

Active system consists of spring and actuator, where actuator act as external power supplied to overcome the force act on the system. Semi-active system is known the intermediate ways to counter these problems due to the limitation of passive system to provide the flexible damping force in isolating various frequencies from engine and due to the drawback of complexity of active system. Engine excitation is extreme at idle condition within frequency range $5 \sim 20 \mathrm{~Hz}$ while at driving condition the frequency range about $20 \sim 250 \mathrm{~Hz}$. Therefore a variable engine mount that can be operated within both conditions is needed [1]. Thus a semi-active engine mount is used to satisfy the variable range of frequency problem. Car makers put much effort to satisfy both condition by tuning the

\footnotetext{
* Corresponding author: razali.yunos@utem.edu.my
} 
stiffness of each engine mount. Design of Experiment DOE methods which is using ADAMS software is a specific method to optimize those parameters as one of the commonly used technique [2]. Besides that, different approach was proposed by repositioning the engine mounts which also affects the dynamic stiffness of the engine mount [3]. In addition, the simulation approaches were used widely for testing and parameter estimation of the engine mounts in order to reduce cost and time [4]. It is undeniable that the semi active damper in engine mounts is step up approach in isolating variable range of frequency.

\section{MR engine mount as semi-active damper}

Various kinds of semi-active devices are currently available [5]. There are semi-active devices that can generate damping force from viscous/visco-elastic-plastic fluids [6]. MR damper falls into this category and currently become the subject of many researches. MR dampers contain controllable fluids that can change their properties when exposed to magnetic fields. By controlling the current to an electromagnetic coil inside the piston of the damper, the MR fluids viscosity can be changed, resulting in continuously variable real time damping system. The application MR damper in engine mount in vehicle was first implemented on 2011 by Porsche. They implements the magnetorheological (MR) technology for the engine mounts of its seventh-generation 911 Turbo which is part of a strategy to bring added smoothness and refinement to the power train, as well as contributing to enhanced cornering and traction capabilities. The system uses magnetically "soft" iron particles, suspended in a synthetic base fluid, held within a cavity in the rubber body of the mount. When a magnetic field is applied by a coil, the particles become aligned, increasing the shear stress and therefore the resistance to flow. The stronger the magnetic field, the higher the dynamic rate of the system. An MR damper is reasonably a latest damping device, in which the magnitude of the resisting force upon a mechanical structure can be adjusted in real time. Adjustment takes place by altering the amount of current passing through wires fixed in the damper. Its characteristics have been studied through both numerical simulation and laboratory tests.

\section{Work principle of MR engine mount}

A schematic of the fabricated engine mounts is shown as Fig.1. The MR engine mounts consists of a four orifice, wire coil, piston, piston rod, oil seals, inner chamber, upper cover, bottom cover, bracket, ball joint and $250 \mathrm{ml}$ MR fluid. The chamber is the working area for piston passing through the MR fluids. The upper cover and bottom cover serve to prevent the MR fluids flow out from the inner chamber. While, the oils seals used at the moving piston area to prevent the MR fluid flow out. Mounting bracket is designed on the bottom cover. Moreover, spring is using as to support the static and dynamics load from the engine

The ball joint is used as the main component and take responsible to transfer forces from the engine to the piston in one direction. It moves linearly during compression and extension. The socket which is connecting to the piston provides free working space for the ball joint to move. Four orifices with diameter $3 \mathrm{~mm}$ drilled on the piston to let the MR fluids pass through. Coiled copper wire around the piston meant to generate magnetic field when current supplied on it. A total of 1200 winding wires were wrapped around the circumference of the piston. This is the maximum number of turns that can be made on the provided piston area. The circumference had been insulated wire with araldite to avoid reaction between MR fluids and the winding cooper wire. Furthermore, the maximum 
current to the electromagnet in the magnetic choke is 1.0 Ampere and the coil resistance is $25 \mathrm{Ohm}$ and the maximum stroke produce is $10 \mathrm{~mm}$.

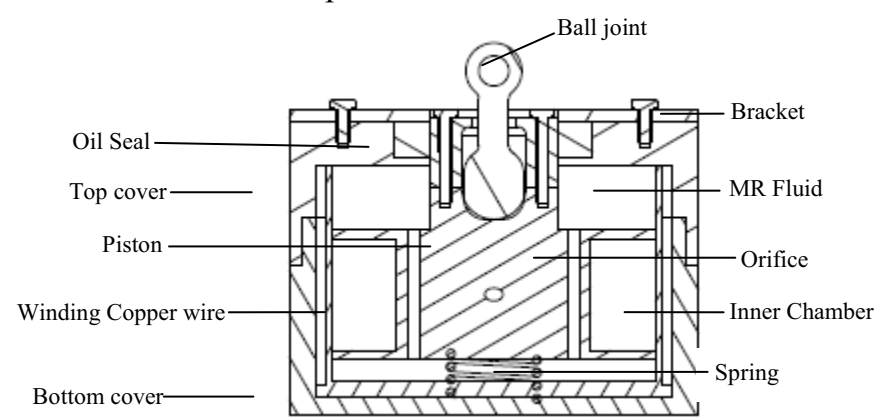

Fig. 1. Schematic of MR engine mounting design

\section{Design of MR engine mount test rig structure}

The key design specification for the MR damper test rig is sufficiently stiff in all frequency ranges of operation. The MR damper test rig structure constructed as stiff as possible in order to absorb the unwanted structural vibration. Several efforts were performed to make the structure as stiff as possible in the most critical directions particularly in vertical plan of the towering structure, side to side towering of the vertical structure and stiffening the vertical sliding shaft. To protract side to side towering of the MR engine mount test rig, diagonal braces were welded to form a diagonal structure with the vertical frames. These additional frames are useful for maintaining torsional rigidity of the structure as well as to prevent torsional bending caused by the unwanted rotational vibration. Stiffening the sliding shaft was performed by holding the shaft edges on the vertical structure and the basement rectangular frame. The solid plate was joined with a sliding bush or well known as sliding bearing at the two main posts as shown in Figure 2.

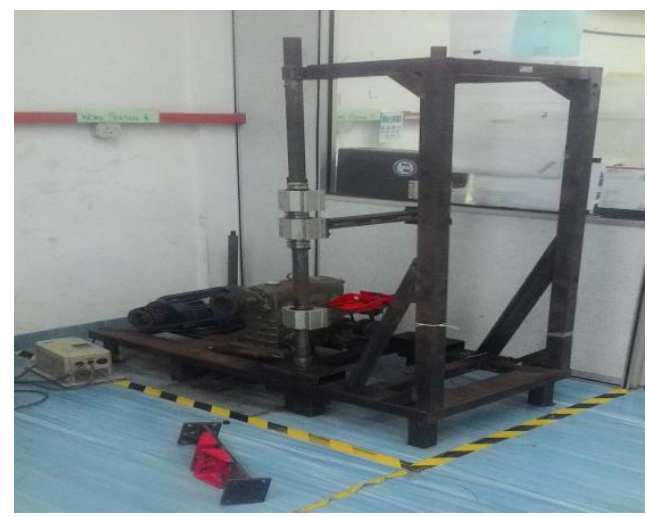

Fig. 2. Sliding bearing. 


\section{Test rig actuation system}

A common test procedure for the MR damper characterization requires a number of actuators such as pneumatic cylinders [7], a hydraulic cylinder [8] and the slider crank mechanism. In an effort to generate a sinusoidal profile, pneumatic and hydraulic actuators requires additional equipment such as compressors, pumps, pipes and control devices. The slider crank mechanism has been chosen in this study because of the cheaper cost and easier to fabricate. Movement of the slider crank mechanism consists of the slide crank assembly, reducer gearbox, 3-phase motors and three phase motor drive. In an effort to identify the criteria of MR engine mount, a moving slider crank mechanism is mounted to the MR engine mount test rig. Reducer gear box consists of a pair of worm gears with a power capacity of $3.7 \mathrm{~kW}$, sufficient to test the MR engine mount. In this project, the gear reducer with a transmission ratio of 10:1 was selected.

Reducer gear can be installed onto the flange, foot or shaft mounting solutions. In this test rig, foot mounting have been employed because of its simplicity and easy installation. Gear reducer covered by casing made of cast iron provides maximum strength for maximum durability, high accuracy, high overload capacity and stable transmission with lower vibration and noise. Efficient heat dissipation and lubrication for longer operating life provided by a major oil reservoirs. Meanwhile, lubrication pipe plugs allow easy fill. Worm gear reducer coupled with 3-phase motor by the B-type V-belt with a girth of 43 inches. MS-series 3-phase motor made by DELTA ELE is used to authorize on the amount of $5 \mathrm{HP}$ or $3.7 \mathrm{~kW}$. The maximum speed of the motor can produce about $1500 \mathrm{rpm}$. Mount the foot which has a frame $112 \mathrm{M} 4$ was selected because of the simplicity in installation.

While performing experiment on MR engine mount, some frequencies have been used to produce different experimental conditions. By using 3-phase motor drive, motor speed can be regulated depending on the requirements. In addition, the main reason to use the variable drive speed is to reduce costs and extend the motor life itself. The motor drive working principle is as diverse driving frequencies. It is an electronic controller that adjusts the speed of electric motors regulates the frequency of electric voltage. Variable frequency drive also reduces the mechanical and electrical stresses on the motor, so it will prolong motor life. 3-phase motor drives used in this study. There are two types of sensor used in this test which are Linear Variable Displacement Transducer (LVDT) to measure the displacement and relative velocity of the damper while the Load Cell sensor to measure the damper force. The National Instrument (NI) card device provides signal processing of the transducers and excitation signals of the slider crank actuator system. These signals are digitally processed and stored in a personal computer using MATLAB Simulink 2009B. Control signals to the MR damper are converted to analogue signals by NI card device. Then, the voltage signals are passed through current driver and sent to the MR damper.

\section{Conclusion}

A MR engine mount test rig has been developed for laboratory testing of MR damper characterization. The limitation of the small peak-to-peak distance of the MR damper is challenging. The sliding mechanism is self-fabricated according to the limitation have solved the problem. The sliding component installed on the structure is aligned properly in resulting smooth running during the experiment. The well software set up give promising results from the sensors used. The MR engine mount testing was successfully done by applying a cyclic motion between the upper and lower ends of the MR engine mount for different values of applied currents to the dampers coils. 
Figure 3 above shows the harmonic motion graph which are the results from the up and down movement of the piston. The increasing force in each different current is effect from the generated magnetic field increase as the current increase. The increasing magnetic field leads the increasing of the viscosity of MR damper. Therefore, high viscosity generates large resistance force to passing through the orifice resulting in high damping force generation.

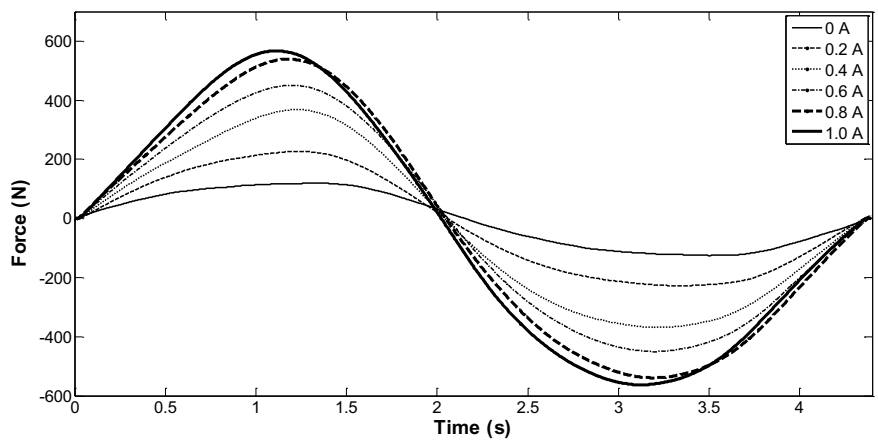

Fig. 3. Measured forces for five constant current levels

This work was financially supported by Short Term Research Grant from Universiti Teknikal Malaysia Melaka (UTeM).

\section{References}

1. C. Ciocanel, T. Nguyen, C. Schroeder, M.H. Elahinia, Performance Evaluation of a Semi-Active Magnetorheological Mount. SAE Technical Papers. 10.4271/2008-010429, (2008)

2. A. Keshavarz, M. Bayani Khaknejad, S. Azadi, Improving Vehicle NVH Behavior via Tuning the Engine Mount Stiffness Using DOE Method. SAE Technical Paper 201101-1510, (2011)

3. Z. Mohd Ripin, L. E. Ooi, Dynamic Characterization of Engine Mount at Different Orientation Using Sine Swept Frequency Test. Regional Conference on Mechanical and Aerospace Technology, Bali, (2010)

4. P.A.G. Zavala, M.G. Pinto, R. Pavanello, J. Vaqueiro, Experimental and Computational Simulation Approaches for Engine Mounting Development and Certification. SAE Technical Paper 2000-01-3239, (2000)

5. J. Wang, G. Meng, Proc. Inst. Mech. Eng., Part L., 215, 165-174, (2001)

6. M. Elahinia, C. Ciocanel, T.M. Nguyen, S. Wang, Smart Mater. Res., 2013, 21, (2013)

7. K. Hudha, H. Jamaluddin, P. Samin, R. Rahman, International journal of vehicle autonomous systems, 3, 230 (2005)

8. F.D. Goncalves, J.D. Carlson, J. Phys.: Conf. Ser., 149, (2009) 